Bulgarian Academy of Sciences. Space Research and Technology Institute. Aerospace Research in Bulgaria. 32, 2020, Sofia

DOI: https://doi.org/10.3897/arb.v32.e01

\title{
COMPARISON OF RADIATION MEASUREMENTS BY BTN AND R3DR INSTRUMENTS OUTSIDE INTERNATIONAL SPACE STATION
}

\author{
Tsvetan Dachev ${ }^{1}$, Jordanka Semkova ${ }^{1}$, Borislav Tomov ${ }^{1}$, Yury Matviichuk ${ }^{1}$, \\ Plamen Dimitrov ${ }^{I}$, Nikolay Bankov ${ }^{I}$, Rositza Koleva ${ }^{I}$, Malina Jordanova, \\ Maxim Litvak ${ }^{2}$, Igor Mitrofanov ${ }^{2}$, Dmitry Golovin ${ }^{2}$ Alexander Kozyrev', \\ Alexey Malakhov', Maxim Mokrousov ${ }^{2}$, Anton Sanin', Vladislav Tretyakov', \\ Viacheslav Shurshakov ${ }^{3}$, Victor Benghin ${ }^{3}$, Olga Ivanova ${ }^{3}$ \\ ${ }^{1}$ Space Research and Technology Institute - Bulgarian Academy of Sciences \\ ${ }^{2}$ Space Research Institute - Russian Academy of Sciences \\ ${ }^{3}$ Institute of Bio-medical problems, Moscow, Russia
}

Keywords: Radiation Measurements, International Space Station

\begin{abstract}
The article presents the first attempt to analyze data obtained simultaneously by the Russian BTN and Bulgarian R3DR instruments, flown in 2010 on the "Zvezda" module of the International space station (ISS). Both instruments have well established sensitivity against gamma radiation. This was verified in space, when the Russian spacecraft Soyuz TMA-16, initially docked to the aft port of the "Zvezda" module, was relocated to the zenith-facing port of the "Poisk" module on January 21, 2010. This maneuver brings a gamma ray source in the angle of view of both the BTN and R3DR instruments. The comparison of the data, after the relocation, for the first channels of the spectrometers reveals that they are elevated. This situation continues till March 18, 2010 when Soyuz TMA-16 spacecraft was undocked from the ISS and landed. The final part of the paper, investigate the decrease of the R3DR instrument dose rates in the region of the South Atlantic anomaly (SAA), generated by the additional mass of the Soyuz TMA-16 spacecraft.
\end{abstract}

\section{Introduction}

Following the European Space Agency announcement of opportunity in 1996 for "Externally mounted payloads for $1^{\text {st }}$ utilization phase" on the ISS, scientists working in the fields of astrobiology proposed experiments, aiming at long-term exposure of a variety of chemical compounds and extremely resistant microorganisms to the hostile space environment [1]. The radiation fields encountered in this environment is of pivotal interest to astrobiology [2]. To provide information about the diurnal variation of this radiation, the EXPOSE-R platform (Fig. 1) accommodated the Radiation Risk Radiometer-Dosimeter (R3D) for the Russian segment (R) R3DR (pls. look at the red oval in Fig. 1). This is a low-mass 
and small-dimension automatic device measuring solar UV and visible radiation in four channels and cosmic ionizing radiation during the EXPOSE-R mission in 2009-2010 [3].

The BTN-MD detection block is a spectrometer with four individual neutron detectors. BTN-MD is a spare flight unit of High energy neutron detector (HEND) experiment; installed on-board NASA spacecraft Mars Odyssey, intended for the exploration and cartography of neutron radiation of Mars surface in different energy ranges [4]. After several years of successful operation of HEND it was decided to use a spare flight unit for the near Earth measurements on-board the ISS [5]. The Russian Zvezda module was chosen for this. Some preparations were made, such as development of the BTN-ME inner control block and the Block-MF (a system for providing temperature conditions) and a special mounting pylon for the BTN-MD outside the station [5].

On Fig. 1 shows the mounting position of the EXPOSE-R facility at the left side of the Russian Zvezda module of the ISS (only part of it is seen). The BTN detector unit is seen in the zenith area of the module. Both units are at distance of about $5 \mathrm{~m}$.

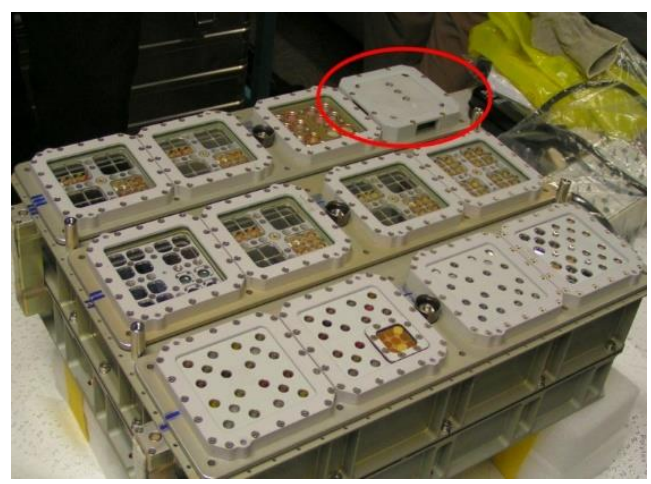

Fig. 1. ESA EXPOSE-R facility

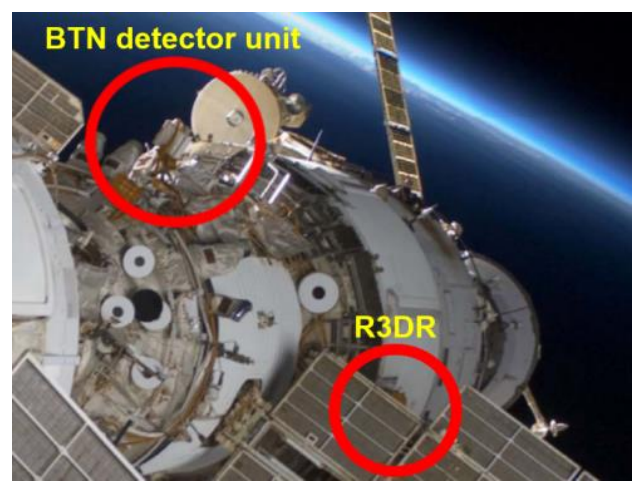

Fig. 2. Position of the BTN detector unit and R3DR instrument outside "Zvezda" module of the ISS

\section{Materials and Methods}

\section{R3DR instrument description}

The R3DR instrument is a Liulin-type miniature spectrometer-dosimeter [6]. Its size is $76 \times 76 \times 34 \mathrm{~mm}$ and weight about $0.12 \mathrm{~kg}$. The alignment of the four photodiodes of the solar irradiance spectrometer is well seen in the centre of the R3DR instrument in Fig. 1. The ionizing radiation PIN diode with a $2 \mathrm{~cm}^{2}$ area is located beneath the aluminium cover and is therefore not visible. 
The ionizing radiation detector of the R3DR instrument (silicon PIN diode of Hamamatsu S2744-08 type) was mounted about $3 \mathrm{~mm}$ below the $1 \mathrm{~mm}$ thick aluminium cover plate. Additionally, there was a technological shielding of $0.2 \mathrm{~mm}$ copper and $0.2 \mathrm{~mm}$ plastic material, resulting in less than $0.6 \mathrm{~g} \mathrm{~cm}^{-2}$ total shielding. This allows measuring the direct hits of electrons with energies higher than $1.18 \mathrm{MeV}$ and of protons with energies higher than $27.5 \mathrm{MeV}$ (https://www.nist.gov/ $\mathrm{pml} / \mathrm{stopping-power-range-tables-electrons-protons-and-helium-ions).} \mathrm{The} \mathrm{surface}$ of the detector $\left(2 \mathrm{~cm}^{2}\right.$ by $0.3 \mathrm{~mm}$ thickness) was oriented to the open space. The detector shielding, being larger from the sides and from behind (Fig. 1), stops the outer radiation belt $(\mathrm{ORB})$ relativistic electrons and attenuates the lower energy inner radiation belt (IRB) protons, but practically does not change the amount of the galactic cosmic rays (GCR) particles.

The instrument obtained one-fixed voltages of $+15 \mathrm{~V}$ DC from EXPOSE-R facility. The telemetry output from the instrument was arranged as an RS422 serial interface with a maximum rate of $19.2 \mathrm{kbps}$. The instrument was controlled by a master microprocessor, containing a 12-bit analogue-to-digital converter (ADC) for the UV data channels and the multiplexer. The ionizing radiation dose and the flux measurements were arranged by a charge sensitive preamplifier and another fast 12-bit ADC. The slave microcontroller determined the deposited energy spectrum. Then the spectrum was transferred to the master micro-controller and to the telemetry system. The measurement cycle of the instrument was fixed at 10s. During this time, one energy deposition spectrum from the cosmic ionizing radiation channel was accumulated. A pulse height analysis technique was used for obtaining the deposited energy spectrum, which is further used for the calculation of the absorbed dose and flux in the silicon detector [7].

\section{Data analysis and dose interpretation procedure}

The main measurement unit in the ionizing radiation spectrometer was the amplitude of the pulse, after the preamplifier, generated by particles or quanta hitting the detector. It is proportional to the energy loss in the detector by a factor of $240 \mathrm{mV} \mathrm{MeV}^{-1}$ and likewise to the dose and the linear energy transfer of the particle. These amplitudes were digitized and organized in a 256-channel spectrum, using only the first 8 bits of the 12 bit fast ADC. The dose $\mathrm{D}(\mathrm{Si})$ in Grey [Gy], which by definition in System International is one Joule deposited in $1 \mathrm{~kg}$ of material, was calculated by dividing the summarized energy deposition in the spectrum in $\mathrm{J}$ by the mass of the detector:

$$
D(G y)=\sum_{i=1}^{255} N_{i} E_{i} M D^{-1},
$$


Where $M D$ is the mass of the detector in $\mathrm{kg}, \mathrm{N}_{i}$ is the number of pulses registered in channel "i", $E_{i}$ is the deposited energy (in Joules, known through the calibration of the detector) corresponding to channel "i".

The calibration procedures, which were performed with analogical R3DR instruments, are described in [8]. The response curve of the R3DR instrument is expected to be very similar to that published by [9] because all Liulin instruments were manufactured using the same electronic parts and the same schematic/scheme. In the specific example of the calibration, performed by Dr. Yukio Uchihori, it was found that the linear coefficient of the response curve, obtained during the calibrations with protons, $\mathrm{He}^{+}$and $\mathrm{Ne}^{+}$ions was equal to $81.3 \mathrm{keV}$, whereas the Liulin instruments predicted $81.4 \mathrm{keV}$. During the calibration process of the new Liulin-type instruments, we adjusted the position of the first spectrometric channel using a ${ }^{241} \mathrm{Am} 60 \mathrm{keV}$ gamma line. Furthermore, the linearity is controlled by electronic methods, as described by AMPTEK INC. in the A225 preamplifier operating notes (http://www.amptek.com/pdf/a225.pdf).

During the calibrations of the Liulin-type instruments it was found that the absolute values of the measured doses were within $2.8 \%$ and $8 \%$ of the reference value for the ${ }^{137} \mathrm{Cs}$ and ${ }^{60} \mathrm{Co}$ sources, respectively [10]. The response of the LIULIN-4 spectrometer (identical in construction to R3DR2 instrument) was compared in [11] to that of the HAWK TEPC (http://www.fwt.com/detector/fwad1ds.htm) on 42 aircraft flights in 2003-2004. On all flights, the absorbed dose measured by both instruments agreed to within $5 \%$. We consider that the flux and dose rate errors of the R3DR measurements on the ISS are within 10\% (interval).

The calibrations showed that except for charged energetic particles, the Liulin instruments has sensitivity towards gamma rays, which allowed monitoring of the natural background radiation [10]. The detector's neutron effectivity is minimal for neutrons with energy less than $0.5 \mathrm{MeV}$ and has a maximum of a few percent for neutrons with energy of $50 \mathrm{MeV}$ [12]. The Hamamatsu PIN diodes of type S2744-08 "neutron induced nuclear counter effect" was described by [13]. Via this effect, neutrons could be observed in all channels of the spectrum.

\section{Radiation sources selection procedure}

The simplest method for source separation is described by Dachev [7], who used the $1971 \mathrm{~J}$. W. Haffner's [14] experimental formulation of the dependence between the incident energy of incoming protons $E_{p}$ and electrons $E_{e}$ and the dose to flux ratio $(\mathrm{D} / \mathrm{F})$ in $\mathrm{nGy} \mathrm{cm}^{2}$ particle ${ }^{-1}$ :

$$
D / F\left(E_{e}\right)=6 \times 10^{-9} E_{e}^{-0.9}+2.5 \times 10^{-8} E_{e}^{0.15}
$$

and 
The valid ranges for formulae (2) and (3) are $1 \div 10 \mathrm{MeV}$, and $1 \div 1000 \mathrm{MeV}$, respectively.

Dachev [7] shows that according to formulae (2) and (3) the data can be simply split into two parts by using the dose to flux ratio (D/F). When the $\mathrm{D} / \mathrm{F}$ is less than $1.12 \mathrm{nGy} \mathrm{cm}^{2}$ particle ${ }^{-1}$, the expected predominant type of radiation in a 10-s interval is ORB electrons. When the $\mathrm{D} / \mathrm{F}$ is greater than $1.12 \mathrm{nGy} \mathrm{cm}{ }^{2}$ particle ${ }^{-1}$, the expected type of radiation is IRB or SEP protons [15]. The GCR source spans the two ranges. The GCR source was identified by the requirements that their dose rates are less than $15 \mu \mathrm{Gy} \mathrm{h}^{-1}$.

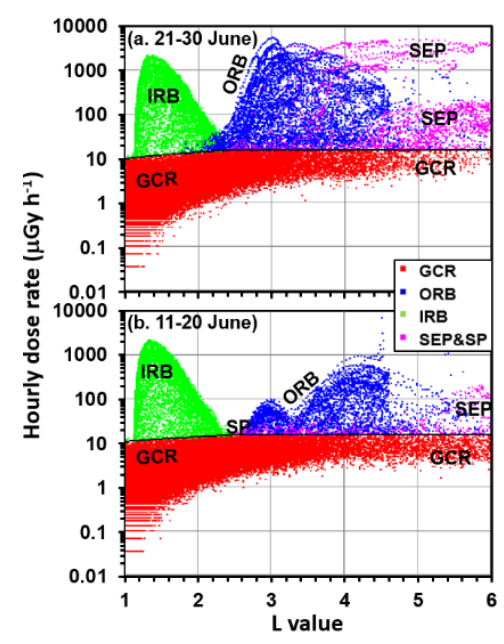

Fig. 3. Latitudinal distribution of the dose rates measured with the R3DR2 instrument

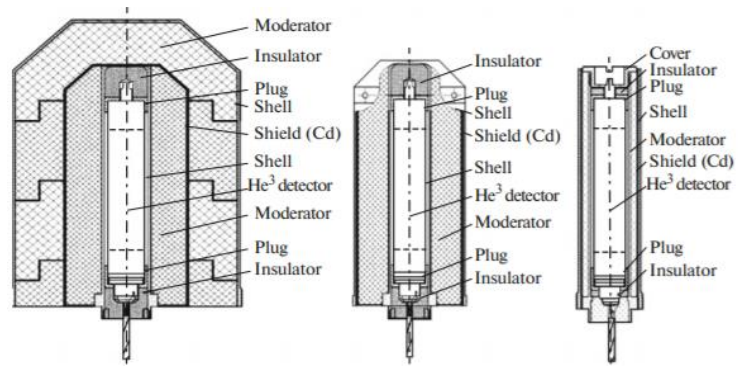

Fig. 4. Design features of BTN-MD instrument

The procedure described by Dachev et al. [15] was upgraded. The result of the separation of the four radiation sources (including SP) is seen in Fig. 3, revealing the latitudinal distribution of the dose rates against McIlwain's $L$ values. The $L$ value is plotted on the x-axis. On the $y$-axis, the absorbed dose rate measured by the R3DR2 instrument is plotted. Fig. 3a contains data from 21 June to 30 June 2015, whereas the data on Fig. $3 \mathrm{~b}$ are from 11 June to 20 June 2015. Each section contains 86400 points at a 10 -s resolution $(10$ days $\times 360 \times 24 \mathrm{~h}$ ).

Four different primary radiation sources, separated by the heavy black lines, are seen in the data. These sources are plotted in Fig. 3 with different colors for the IRB, ORB, GCR and SEP sources. From one 10-s independent measurement of the dose rate (D) and flux (F), we were able to calculate one dose to flux ratio (D/F). 
Using this, we were able to decide only what the predominant radiation sources were, but we were not able to extract the exact doses of each source.

The GCR source contributes for the majority of the measurements in Fig. 3, visualized as the area with many red points in the bottom over the L-value range between 1 and 6 . The dose rates vary between 0.03 and $15 \mu \mathrm{Gy} \mathrm{h}^{-1}$.

The second permanent source of radiation corresponds to the protons in the SAA region of the IRB, presented as a large maximum in the upper left corner of Fig. 3, with a total of 5876 points in Fig. 3a. They cover L-values between 1.2 and 2.6. The dose rates in the IRB region varied between 10 and $2748 \mu \mathrm{Gy} \mathrm{h}^{-1}$.

The GCR and IRB sources in both figures $3 \mathrm{a} / \mathrm{b}$ look very similar because these two sources have relatively slow time variations. Drastically different are the ORB and SEP sources in the right parts of Figures $3 \mathrm{a} / \mathrm{b}$. The reasons for the radically different ORB and SEP distributions are the magnetic storms on 23 and 25 June and the SEP events on 18, 22 and 26 June 2015. The real SEP particles in Fig. 3a/b appear at some smaller L-values. Then they rise and finally maintain some fixed dose rate value at a range of $L$ from 4 to 6 . The SEP source in Fig. $3 b$ appears only at $L>5$, because the SEP event on 18 May was very week.

The boundary seen at $\mathrm{L}=4.7$ in the ORB source in figures $3 \mathrm{a} / \mathrm{b}$ is generated by the Earth magnetic field hemisphere asymmetries. The ISS orbit in the Southern hemisphere is extended up to $L=6$, while in the Northern only up to $L=4.7$.

\section{BTN instrument description}

Three detectors (SD, MD, and LD) are based on helium-filled $\left({ }^{3} \mathrm{He}\right)$ proportional neutron counters covered in cadmium shields and polyethylene spheres of different thickness. The design aspects of these detectors are shown in Fig. 4. The proportional ${ }^{3} \mathrm{He}$ counters are detectors of epithermal neutrons. In this case, having given a good account (also as a part of the HEND experiment flight unit), the LND2517 industrial counters (LND Inc. Company, United States) were used, filled with ${ }^{3} \mathrm{He}$ and a small addition of $\mathrm{CO}_{2}$ under an atmosphere pressure of 6 . The registration concept in the proportional counter is based on the capture of a thermal or epithermal neutron in a reaction of that type as follows:

$$
\mathrm{n}+{ }^{3} \mathrm{He} \rightarrow{ }^{3} \mathrm{H}+\mathrm{p}+764 \mathrm{keV}
$$

The total energy output in that reaction is distributed between the proton and the triton in the ratio of $191 \mathrm{keV}$ (triton) and $573 \mathrm{keV}$ (proton) in inverse proportion to their masses. 


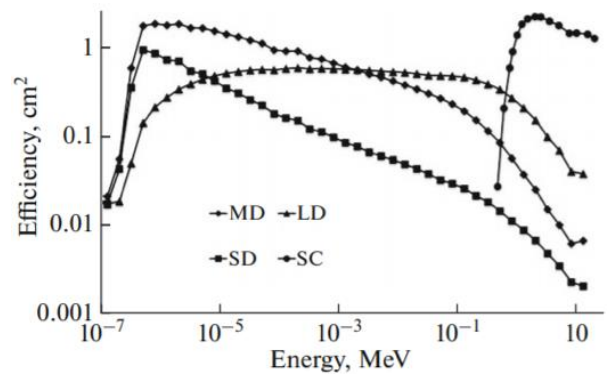

Fig. 5. Sensitivity functions for all BTNMD instrument detectors

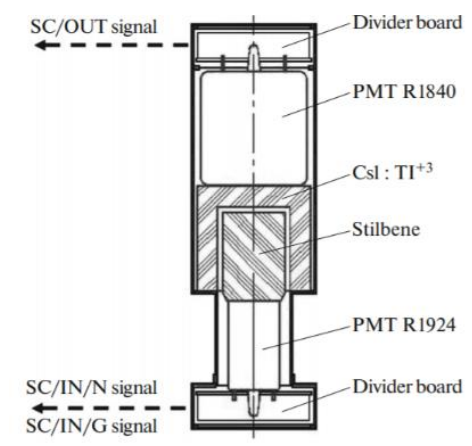

Fig. 6. Scintillation block configuration

The counter itself is a metallic cylinder (cylinder jacket serves as a cathode) with a thin (thickness about the fraction of a millimetre) tungsten wire along the cylinder axis, which serves as the anode. A current of about $1 \mathrm{kV}$ is applied between the cathode and the anode. This allows the counter to work in the so-called proportional mode, when the applied current is high enough for the primary electrons formed during the ionization of gas molecules by a nuclear reaction of $\mathrm{n}+{ }^{3} \mathrm{He} \rightarrow{ }^{3} \mathrm{H}$ $+p$ in order to perform secondary ionization with the generation of a large number of ion pairs. The collected charge on the electrodes of the counter and the corresponding current impulse is proportional to the full energy output in the volume of the counter. The digitalization of the signal received, during one neutron registration act, allows the amplitude spectrum to be obtained.

We used 16 spectral channels to digitalize amplitude. The first 15 spectral channels have approximately equal width and cover energy range up to $1 \mathrm{MeV}$. The last channel is integral and allows particles that produce energy output greater than $1 \mathrm{MeV}$ to be registered (these particles may be, e.g., high-energy neutrons). The amplitude spectrum form measured in this proportional counter depends on the kinematics of the reaction products and does not depend on the energy of the incoming neutron (except episodes of high-energy neutron registration). The typical form of the amplitude spectrum has a main peak that corresponds to the full energy output ( $764 \mathrm{keV}$ when both the proton and triton stayed in the volume of the detector) and a wide low-energy plateau that corresponds to the episode when a proton or a triton reached the walls of the detector (wall effects). The cross section of a neutron capture starts in the thermal energy ranges (fractions of eV) and extends to the epithermal energies (units and tens of $\mathrm{keV}$ ) according to the power law $\sim \mathrm{E}^{-1 / 2}$. If a proportional counter is covered in a layer of a cadmium (effective thermal neutron absorber), its registration efficiency shifts to an epithermal-neutron energy range of $0.4 \mathrm{eV}$ (cadmium threshold) to hundreds of $\mathrm{eV}$.

To increase the energy range of the registered neutrons (suitable for registering neutrons with higher energies), all detectors of the BTN-MD instrument 
are covered in polyethylene $(\mathrm{CH} 2)$ with various thicknesses. The polyethylene is an effective neutron moderator due to the hydrogen in its composition. The various thickness of the polyethylene leads to various moderation rates of incoming neutrons to energies where the registration efficiency in gas-filled counter approaches the maximum.

An SD detector (Fig. 4 to the right), with a polyethylene thickness of $2 \mathrm{~mm}$, has the maximum response to the neutron in the energy range of $0.4 \mathrm{eV}$ to $1 \mathrm{keV}$. The MD detector (Fig. 4 at the centre), with a thickness of medium polyethylene about $15 \mathrm{~mm}$, has maximum response to neutrons in energy range from $10 \mathrm{eV}$ to $100 \mathrm{keV}$. LD detector, (Fig. 4 to the left) with a double polyethylene thickness of 30 $\mathrm{mm}$, has the maximum response to neutrons in energy range from $10 \mathrm{eV}$ to $1 \mathrm{MeV}$. Figure 5 shows the sensitivity functions of all detectors in the BTN-MD instrument. It is clearly seen that, due to various thicknesses of the moderators, in the proportional counters, we managed to succeed in registering neutrons in a wide range of energies of from $0.4 \mathrm{eV}$ up to $1 \mathrm{MeV}$.

The fourth detector (SC) is intended to register only high-energy neutrons in the energy range of $350 \mathrm{keV}$ to $15 \mathrm{MeV}$. It was manufactured from a stilbene crystal $(\mathrm{C} 14 \mathrm{H} 12)$ and covered in the anticoincidence shield from the crystal. The configuration of the scintillation block is shown in Fig. 6. The fast neutron detector is also shown there (in Fig. 6, it is marked as a stilbene). The stilbene is an organic crystal with high hydrogen content. Upon registering a neutron with energy En, a proton with energy Ep $<$ En is dislodged (SC/IN/N signal shown in Fig. 6).

The registration of gamma rays with the formation of a free electron also occurs in the stilbene (SC/IN/G signal). The forms (time profile) of the electric pulses from the protons and the electrons differ very much, so the special electric scheme developed for the BTN-MD allows these two events to be divided with an error of no more than $10^{-3}$.

The outer scintillation detector (signal measured in the detector SC/OUT, see Fig. 6) was manufactured from a crystal, which has a high density and an atomic number, which allows the high registration efficiency of gamma rays and charged particles with the energies of more than $50 \mathrm{keV}$. To distinguish the outer cosmic rays, the protons from the recoil protons formed in stilbene after the interactions with the neutrons, an anticoincidence logic was implemented in the detector block. The proton registration of the cosmic rays act in the outer detector SC/OUT is followed by the VETO signal, which forbids the simultaneous registration of that proton in the inner detector SC/IN.

\section{ISS configuration during the R3DR and BTN simultaneous operation}

In November 2006, the BTN MD neutron spectrometer was installed onboard the Russian Zvezda module, which is a component of International Space 
Station (ISS). The R3DR dosimeter worked in the EXPOSE-R facility outside the Russian Zvezda module of the ISS in the period 11 March 2009-20 August 2010.

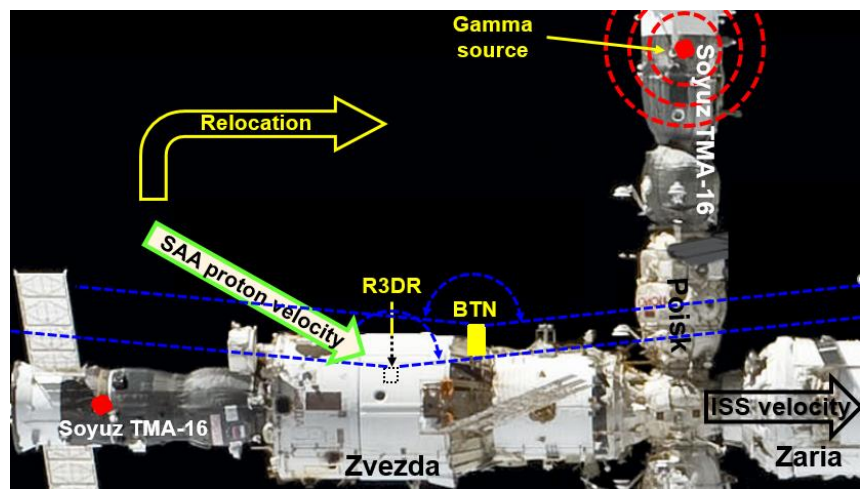

Fig. 7. The configuration of the Russian segment and the positions of both the BTN detector unit and the R3DR instrument

Because of a failure of the computer, connecting the external facility to the ISS and to the ground [16], no data were retrieved in three large time spans: 24 June-28 December 2009, 21 January-18 February 2010 and 12-21 March 2010.

Figure 7 shows the configuration of a part of the Russian segment during the R3DR and BTN simultaneous operation in the period January-March 2010. On the left bottom, part of the figure is the Zvezda module. The Zaria module is on the right side. The Poisk module is in the middle.

The Soyuz TMA-16 was a crewed flight to and from the ISS. The launch of the Soyuz rocket with the Soyuz TMA-16 spacecraft took place on Sept. 30, 2009, at 11:14:42 Moscow Summer Time. It transported two members of the Expedition 21 crew and a Canadian entrepreneur from the Baikonur Cosmodrome in Kazakhstan to the ISS. Soyuz TMA-16 was docked to the ISS at the aft port of the Zvezda module on Oct. 2, 2009 at 12:35:07 Moscow Time. On January 21, 2010, cosmonaut Suraev and Expedition 22 Commander J. Williams relocated the spacecraft to the zenithfacing port of the Poisk module. Soyuz TMA-16 landed in Kazakhstan on March 18, 2010.

The gamma ray source (red large circle), part of the KAKTUS-2B gamma altimeter is mounted at the bottom of the descending module of the Soyuz TMA-16 spacecraft. It is used to initiate the firing of the boosters during the landing. The position of the BTN detector unit is shown as a yellow rectangle in the figure. Its angle of view is toward up that is why the BTN does not see the gamma source at the Soyuz TMA-16 spacecraft until the moment of the relocation on January 21st, 2010. 

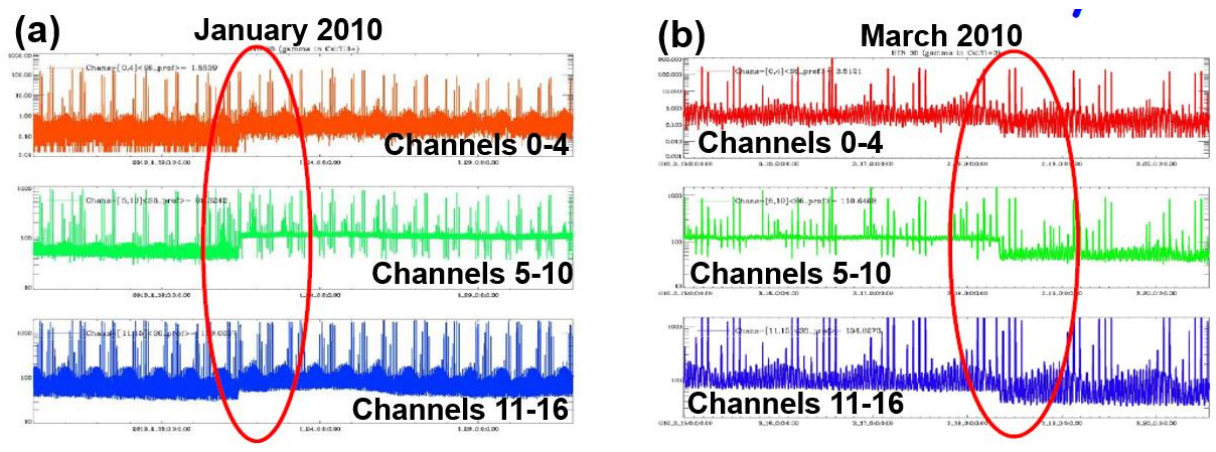

Fig. 8. BTN data obtained in January and March 2010

The R3DR instrument position is shown in Fig. 7 as a black dashed line quadrate. It is mounted on the ESA EXPOSE-R facility and both are behind the body of the Zvezda module and are not visible. The R3DR angle of view (blue lines in Fig. 7 ) is also toward up, analogically to that of the BTN. It does not see the body and the gamma ray source on Soyuz TMA-16 spacecraft before the relocation on 21 of January 2010. R3DR and BTN instruments, being gamma ray sensitive, start to show the gamma radiation in the dataflow after the moment of the relocation on January $21^{\text {st }}$, 2010. On March 18, 2010, when Soyuz TMA-16 spacecraft went to landing, both instruments loose the signal of gamma ray.

\section{Data analysis}

\section{Gamma ray source analysis}

\section{BTN data analysis}

Fig. 8a contains the gamma ray background measurements of the BTN detector unit in the period January $14^{\text {th }}-$ February $1^{\text {st }}$, 2010. Well-seen drop-up in the count rates is observed in all channels, i.e. 1-16, at about 10:30 UT on January $21^{\text {st }}, 2010$. Since this moment up to about 08:00 UT on March 18 (Fig. 8b), the counts in the mentioned channels were elevated because of the quanta emissions of the ${ }^{60} \mathrm{Co}$ gamma ray source at the Soyuz TMA-16 spacecraft. They became visible by the BTN detector unit after the relocation of the Soyuz TMA-16 spacecraft.

Fig. 8b contains the gamma ray background measurements by the BTN detector unit in the period 15-21 March 2010. In this case, a well-seen drop-down in the count rates is observed in all channels from 1 to16 at about 08:00 UT on March 18, 2010. The change is associated with the undocking of the Soyuz TMA-16 spacecraft from the ISS for further landing. This brings the gamma ray source away from the BTN detector unit, which stop to observe it. 


\section{R3DR data analysis}

Fig. 9a visualizes the variations of the R3DR instrument first channel count rate in the period 16-25 January 2010, while Fig. $9 \mathrm{~b}$ - the variations of the periods 6-10 and 22-27 March 2010. With black non-filled points is presented the count rate. The points were selected with the following requirements: a) the total magnetic field strength to be higher than 0.26 Gauss.
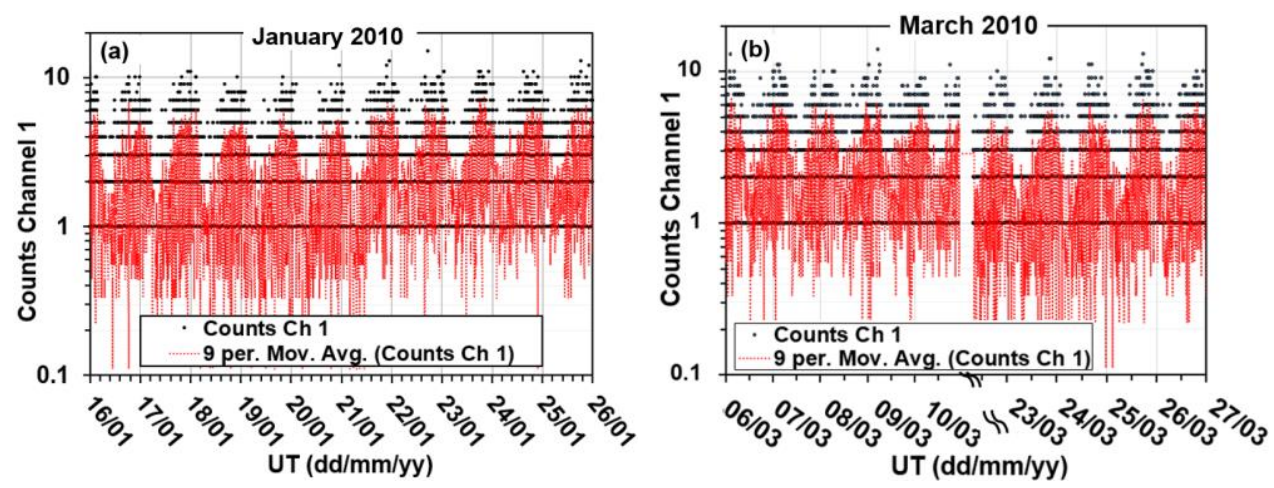

Fig. 9. R3DR data obtained in January and March 2010

This removes from the selection the IRB source protons in the region of the

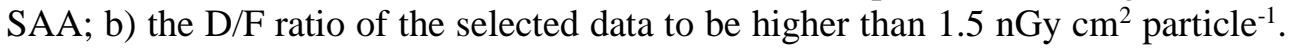
This removes from the selection the ORB relativistic electrons. As a result of both requirements, only the GCR radiation was selected. The red dotted line in the figures presents the moving average per 9 points of the count rate.

The first feature seen in the Fig. 9 is the meander of the minima and the maxima in both variables. This is generated by the orbital movement in the longitude of the ISS during 1 day that is why the meander is with about one day frequency. The minima in Fig. 9 correspond to the crossings of the magnetic equatorial region, while the maxima - to the crossings of the high latitudes in both hemispheres. The geomagnetic shielding, measured by the vertical cut-off rigidity [17], is the reason for the reduced GCR fluxes at low L values and for the rising fluxes toward the high L values. The same meander is observed in the BTN data in Fig. 8.

The second main feature is the drop-up of the count rate around $21^{\text {st }}$ of January in Fig. 9a and the drop-down in the interval between 10 and 22 March 2010 in Fig 9b. Those are the same changes as the observed in Fig. 8. That is why we consider that the R3DR count rate data reflect the observation of the gamma ray source at the Soyuz TMA-16 spacecraft.

Historically, at first the gamma ray source at Soyuz type spacecraft was observed by the R3D-B2 instrument (technologically identical to the R3DR instrument) at the Foton-M2 spacecraft. The R3D-B2 instrument was mounted inside the ESA Biopan-5 facility in ESTEC, The Nederland (Dachev 2013, look at 
Fig. 1 therein) and switched ON in ESTEC on 24 May 2005. It measured the radiation during the whole transportation from ESTEC to Baikonur, Kazakhstan. During the integration of the Biopan-5 facility in the Foton-M2 spacecraft on 29 May an additional source of radiation was observed by R3D-B2 instrument. It rises up the doses from the normal background level of $0.1 \mu \mathrm{Gy} \mathrm{h} \mathrm{h}^{-1}$ up to about $2 \mu \mathrm{Gy} \mathrm{h} \mathrm{h}^{-1}$. Having in mind the very small level of the D/F ratio of about $0.2 \mathrm{nGy} \mathrm{cm}^{2}$ particle $^{-1}$, we identify it as the gamma radiation.

More precisely, the R3DR data analysis gives the following results for the changes of the R3DR parameters on 21 January, connected with the arrival of the Soyuz TMA-16 spacecraft, seen in Fig 9a: a) the average count rate in the first channel rises up from 1.87 to 2.46 counts per $10 \mathrm{~s}$; b) the average GCR dose rate rises up from 7.31 to $7.94 \mu \mathrm{Gy} \mathrm{h}^{-1}$. The calculated average ambient dose rate [18] rises from 27.2 to $29.8 \mu \mathrm{Sv} \mathrm{h}^{-1}$. For the changes, connected with the outflow of the Soyuz TMA-16 spacecraft, seen in Fig 9b the following results were obtained respectively: a) the average count rate in the first channel falls down from 2.22 to 1.91 counts per $10 \mathrm{~s}$; b) the average dose rate fall-down is from 7.59 to $6.53 \mu \mathrm{Gy} \mathrm{h}^{-1}$. The calculated average ambient dose rate [18 falls down from 28.4 to $24.6 \mu \mathrm{Sv} \mathrm{h}^{-1}$.

\section{Analysis of the IRB source decrease}

The analysis of the data from the R3DE instrument of the ESA's EXPOSE-E mission, outside the ISS at the European Technological Expose Facility (EuTEF) on the ESA Columbus module, shows that the docking of the Space Shuttle with the ISS decreased the SAA dose rates [19]. The R3DE instrument decreases were from about $1500-\mu \mathrm{Gy} \mathrm{h}{ }^{-1}$ down to $600-700 \mu \mathrm{Gy} \mathrm{h}^{-1}$ or by a factor of two.

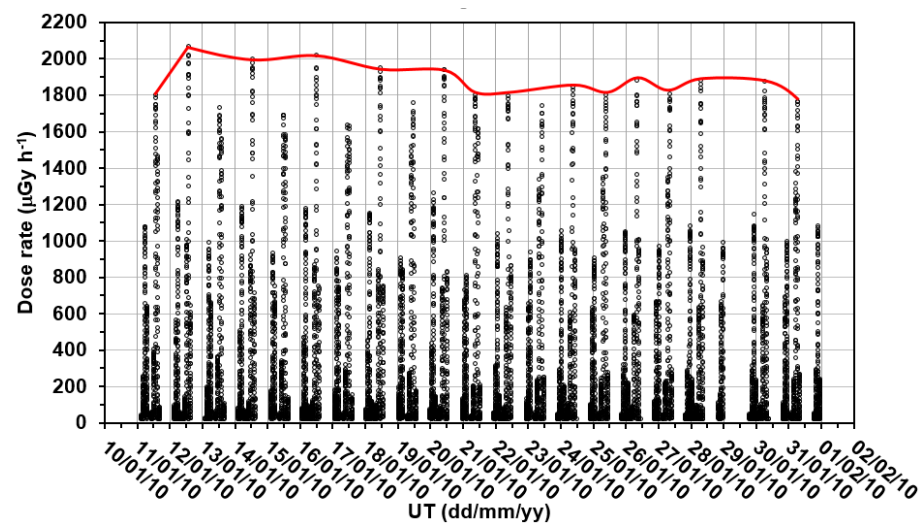

Fig. 10. SAA dose rate variations from 11 to 31 January 2010 
The dose rate data from the R3DR instrument showed that: 1) before the Space Shuttle docking, the SAA dose rates, measured with the R3DR, were higher $\left(\sim 2500 \mu \mathrm{Gy} \mathrm{h}^{-1}\right)$ than the R3DE data; 2$)$ The decrease of the SAA dose rates, after the shuttle docking, was only by a factor of 1.25 . These differences were explained by the smaller shielding of the R3DR from the body of Zvezda module and by the larger distance from the body of the Space Shuttle, docked to the American Destiny module.

Having in mind the above, we decided to prove how the relocation of the Soyuz TMA-16 spacecraft inside of the view angle (pls. look the blue lines in Fig. 7) changes the SAA energetic protons dose rates.

Fig. 10 shows the SAA dose rate variations from 11 to 31 January 2010. The points were selected with the following requirements: a) the total magnetic field strength to be less than 0.23 Gauss. This specify the selection predominately the IRB source protons in the region of the SAA; b) the D/F ratio of the selected data to be higher than $1.5 \mathrm{nGy} \mathrm{cm}^{2}$ particle ${ }^{-1}$; c) the dose rate to be higher than $15 \mu \mathrm{Gy} \mathrm{h}^{-1}$.

Because of the large time interval on the $X$ axis in Fig. 10, the 6-8 dose rate data of the ascending and descending crossings of the SAA anomaly per day are presented only by two bars. The first one corresponds to the descending orbits, while the second one to the ascending orbits during one series of 6-8 crossings. The differences in the dose rate amplitudes are produced by the east-west asymmetries of the proton fluxes in the region of the SAA [20], which lead to the existence of a predominant east to west drift velocity of the protons in the SAA.

In Fig. 7 the proton drift velocity is presented with light green arrow. The picture really visualizes the descending orbits situation, when the station is flying in the direction of the ISS velocity to the right. The R3DR instrument, being at the other side of the Zvezda module (pls. look also Fig. 2), is shielded from the low energy SAA protons by the body of the Zvezda module. That is why, the dose rate in the descending (first) bars in Fig. 10 are smaller than the ascending bars. During the ascending orbits, the ISS is rotated at $180^{\circ}$ and R3DR is directly hit by the SAA protons.

Well seen decrease of the SAA dose rates is observed on 21 January 2010, when Soyuz TMA-16 spacecraft was relocated and came in the angle of view of the R3DR instrument. The red curve, which connected the maximal dose rate bars, underlines this change. More precise, the R3DR data analysis gives the following results for the changes of the R3DR parameters on 21 January, connected with arrival of the Soyuz TMA-16 spacecraft, as seen in Fig 10: a) the average dose rate in the SAA decreases from 360 to $330 \mu \mathrm{Gy} \mathrm{h}^{-1}$; b) the maximal observed SAA dose rate decreases also from 2063 to $1878 \mu \mathrm{Gy} \mathrm{h}^{-1}$. These changes are statistically verified by $441610 \mathrm{sec}$ measurements in the period 11-20 January and 4340 measurements in the period 22-31 January.

The rise of the SAA dose rates, connected with the undocking of the Soyuz TMA-16 spacecraft, on March 182010 are not possible to be precisely analysed, 
because of rotating of the ISS at $180^{\circ}$ on March 3, 2010. The data in the period 6-12 March are not collected in the same way as the data in the period 22-30 March 2010. The result is that both data sets are not possible to be compared.

\section{Conclusions}

The simultaneously obtained gamma ray data by the Russian BTN and the Bulgarian R3DR instruments show very similar changes, connected with the appearance of the gamma ray source in the angle of view of both instruments. The undocking of the Soyuz TMA-16 spacecraft on March 182010 also brings identical changes in both instruments. In conclusion, we are deeply convinced that the first attempt for a mutual data analysis is very successful.

\section{Acknowledgements}

This work is supported by: a) Agreement between RAS and BAS on "Fundamental space research"; b) Contract No. 4000117692/16/NL/NDe Funded by the Government of Bulgaria through an ESA Contract under the PECS (Plan for European Cooperating States); c) Contract with National Science Fund - Bulgaria on Project No. 129 FOR BILATERAL PROJECTS - BULGARIA - RUSSIA 20182019. In IKI-RAS the work is supported by the Russian Science Foundation under grant 19-52-18009.

Most of the data used in this paper are part of the "Unified web-based database with Liulin-type instruments", which are available online, free of charge at the following URL: http://esa-pro.space.bas.bg/database. The database was created under the ESA contract mentioned above.

\section{References}

1. Rabbow, E., Horneck, G., Rettberg, P., Schott, J.-U., Panitz, C., et al., EXPOSE, an astrobiological exposure facility on the International Space Station-from proposal to flight. Orig. Life Evol., Biosphere, 2009, 39, 581-98.

2. Ferrari, F. and Szuszkiewicz, E. Cosmic rays: a review for astrobiologists. Astrobiology 2009, 9, 413-36.

3. Dachev, T. P., G. Horneck, D.-P. Häder, M. Schuster, and M. Lebert, EXPOSE-R cosmic radiation time profile. Journal of Astrobiology, 2015, 14, 17-25.

4. Mitrofanov, I., Anfimov, D., Kozyrev, A., et al., Maps of subsurface hydrogen from the high energy neutron detector, Mars Odyssey, Science, 2002, 297, 5578, 78-81.

5. Tretyakov, V. I., Mitrofanov, I. G., Bobronitskii, Yu. I., et al., The first stage of the "BTNNeutron" space experiment onboard the Russian segment of the International Space Station. Cosmic Res., 2010, 48, 4, 285-99.

6. Dachev, T. P., B. Tomov, Yu. Matviichuk, Pl. Dimitrov, et al., Calibration Results Obtained With Liulin-4 Type Dosimeters. Adv. Space Res., 2002, 4, 917-25.

7. Dachev, T. P., Characterization of near Earth radiation environment by Liulin type instruments, Adv. Space Res., 2009, 44, 1441-49. 
8. Dachev, T. P., J. V. Semkova, B. T. Tomov, Yu. N. Matviichuk, et al., Overview of the Liulin type instruments for space radiation measurement and their scientific results, Life Sciences in Space Research, 2015, 4, 92-114.

9. Uchihori, Y., H. Kitamura, K. Fujitaka, T. P. Dachev, B. T. Tomov, P. G. Dimitrov, and Y. Matviichuk, Analysis of the calibration results obtained with Liulin-4J spectrometer-dosimeter on protons and heavy ions. Radiation Measurements, 2002, 35, 127-34.

10. Spurny, F. and T. P. Dachev, Long-Term Monitoring of the Onboard Aircraft Exposure Level with a Si-Diode Based Spectrometer. Adv. Space Res., 2003, 32, 53-58.

11. Green, A.R., Bennett, L.G.I., Lewis, B.J., Kitching, F., McCall, M.J., Desormeaux, M., Butler, A., An empirical approach to the measurement of the cosmic radiation field at jet aircraft altitudes. Adv. Space Res. 2005, 36, 1618-1626.

12. Spurny, F., Response of a Si-diode-based device to fast neutrons. Radiation Measurements, 2005, 39, 219-23.

13. Zhang, L., Mao, R., and Zhu, R. Fast neutron induced nuclear counter effect in Hamamatsu silicon PIN diodes and APDs. IEEE Transactions on Nuclear Science. 2011, 58, 1249-56.

14. Haffner, J. W., Yadernoe izluchenie i zashchita v kosmose (Nuclear Radiation and Protection in Space), pp 115, Atomizdat, Moscow, 1971. (in Russian), translated from: J. W. Haffner, Radiation and shielding in space. NY: Academic Press, 1967.

15. Dachev, T., Horneck, G., Häder, D.-P., Lebert, M., Richter, P., Schuster, M., and Demets, R. Time profile of cosmic radiation exposure during the EXPOSE-E mission: The R3D instrument. International Journal of Astrobiology, 2012, 12, 403-11.

16. Rabbow, E., Rettberg, P., Barczyk, S., Bohmeier, M., Parpart, A., Panitz, C., ... Reitz, G. The astrobiological mission EXPOSE-R on board of the International Space Station. International Journal of Astrobiology, 2015, 14, 3-16.

17. Smart, D. F. and M. A. Shea, A review of geomagnetic cutoff rigidities for Earth-orbiting spacecraft. Advances in Space Research, 2005, 36, 2012-20.

18. Spurny, F., O. Ploc, and I. Jadrnı'kova, Spectrometry of linear energy transfer and dosimetry measurements onboard spacecrafts and aircrafts. Phys. Part. Nuclei Lett., 2009, 70-77. Pleiades Publishing, Ltd. ISSN 1547-4771.

19. Dachev, T P., Semkova, J., Tomov, B., Matviichuk, Y., Dimitrov, P., Koleva, R., ... Bankov, N. G., Space shuttle drops down the SAA doses on ISS. Advances in Space Research, 2011, 47, 2030-2038.

20. Wilson, J. W., Nealy, J. E., Dachev, T., Tomov, B. T., Cucinotta, F. A., Badavi, F. F., de Angelis, G., Leutke, N., Atwell, W. Time serial analysis of the induced LEO environment within the ISS 6A. Adv. Space Res. 2007, 40, 1562-70. 


\title{
СРАВНЯВАНЕ НА ДАННИТЕ ОТ ПРИБОРИТЕ ВТN И R3DR ИЗВЬН МЕЖДУНАРОДНАТА КОСМИЧЕСКА СТАНЦИЯ
}

\author{
Ц. Дачев, Й. Семкова, Б. Томов, Ю. Матвийчук, П. Димитров, Н. Банков, \\ Р. Колева, М. Йорданова, М. Литвак, И. Митрофанов, Д. Головин, \\ А. Козирев, А. Малаков, М. Мокроусов, А. Санин, В. Третяков, \\ В. Шуршаков, В. Бенгин, О. Иванова
}

\section{Резюме}

Статията представя първия опит за анализ на данни, получени едновременно от руския прибор BTN и българския прибор R3DR, работили на модула "Звезда" на Международната космическа станция (МКС) през 2010 г. И двата прибора имат добре установена чувствителност към гама-льчение. Това беше доказано в космоса, когато руският космически кораб "Съюз TMA-16", който беше скачен към задния порт на модула "Звезда", на 21 януари 2010 г., беше преместен в порта на модула Poisk. В резултат на тази маневра, източник на гама льчи попада в ьгъла на зрение на двата прибора. Сравнението на скоростите на броене в първите канали на спектрометрите показва, че те са повишени. Това продължава до 18 март 2010 г., когато космическият кораб "Съюз ТМА-16" се отделя от МКС и каца. Последната част от статията изследва намалението на дозата от прибора R3DR в района на Южноатлантическата аномалия (ЮАА). Последното е генерирано от допълнителната маса на космическия кораб "Съюз ТМА-16", което допълнително екранира прибора R3DR. Намаляването на потока от ниско енергийни протони води до намаляване на регистрираните дози. 